\title{
Environmental and External Costs of Yali Hydropower Plant and Policy Recommendations in Vietnam
}

\author{
Nguyen Van Song1*, Vu Ngoc Huyen"\#, Nguyen Van Hanh'2, Nguyen Xuan Diep³, \\ Nguyen Xuan Huu', Pham Thanh Lan1, Ho Ngoc Cuong1, Do Thi Diep1, \\ Tran Thi Thu Trang1, Nguyen Thi Minh Phuong5
}

\author{
${ }^{1}$ Faculty of Economics and Rural Development (FERD), Vietnam National University of Agriculture (VNUA), Trauquy, Gialam, \\ Hanoi, Vietnam \\ ${ }^{2}$ Viet Nam Institute of Energy (IEN), Hanoi, Vietnam \\ ${ }^{3}$ Thainguyen University of Economics \& Business Administration (TNUEBA), Thainguyen, Vietnam \\ ${ }^{4}$ Vietnamese Academy of Forest Sciences (VAFS), Hanoi, Vietnam \\ ${ }^{5}$ Vinh University, Vinh, Vietnam \\ Email: *nguyensonghua@gmail.com, ${ }^{*}$ vnhuyen@vnua.edu.vn
}

How to cite this paper: Van Song, N., Huyen, V.N., Van Hanh, N., Diep, N.X., Huu, N.X., Lan, P.T., Cuong, H.N., Diep, D.T., Trang, T.T.T. and Phuong, N.T.M. (2020) Environmental and External Costs of Yali Hydropower Plant and Policy Recommendations in Vietnam. Journal of Environmental Protection, 11, 344-358.

https://doi.org/10.4236/jep.2020.114020

Received: March 20, 2020

Accepted: April 7, 2020

Published: April 10, 2020

Copyright $\odot 2020$ by author(s) and Scientific Research Publishing Inc. This work is licensed under the Creative Commons Attribution International License (CC BY 4.0)

http://creativecommons.org/licenses/by/4.0/

\begin{abstract}
The purpose of this study is to estimate the monetary value of the main environmental and external costs of Yali Hydropower Plant (YHPP) and to incorporate them into the financial viability indices of the plant, namely its net present value and electricity price. The results were found that if the electricity price is kept at its original level of $5.2 \mathrm{US}$ cents/kWh to cover direct costs only, the net present value of the plant would be reduced to about $27 \%$ by incorporating environmental and external costs. Alternatively, the electricity price would have to be increased to $5.68 \mathrm{US}$ cents/kWh in order to cover the full costs of YHPP and to maintain the original net present value. The main policy recommendations are: Government regulations should require that the financial analysis and appraisal of all future electricity sources include the full cost of these schemes, including not only direct costs but also environmental and external costs related to preventing or mitigating the environmental impact caused by them. An appropriate financial mechanism should be established to allocate the revenue from full cost electricity pricing to a fund to cover the environmental protection and compensation costs.
\end{abstract}

\section{Keywords}

Environmental and External Costs, Hydro-Electricity, Electricity Price, Yali Hydropower

${ }^{*}$ First author; ${ }^{*}$ Corresponding author. 


\section{Introduction}

The Yali Hydropower Plant (YHPP) ranks second among the electricity sources of Vietnamese unified national electricity system. This is because of its great electricity potential, high financial viability and favorable plant location for cheap electricity in supplying the central and southern part of Vietnam and for ensuring the stability of running the whole electricity network of the country.

The YHPP is located on Sesan River in the western highland of Central Vietnam where the Thuong ethnic minority tribes live. These tribes have low incomes and special customs and habits. The plant has an installed capacity of 720 MW and an electricity generation of $3600 \mathrm{GWh}$ per annum. This is about $10 \%$ of the total electricity production forecasts for the country in the year 2010 (Institute of Energy, 1998) [1]. The plant construction began in the year 1993 and was completed in April 2002 with an earth fill dam of 12,457,000 $\mathrm{m}^{3}$ embankment volume and a reservoir of $64.8 \mathrm{~km}^{2}$ surface and $1037 \mathrm{Mm}^{3}$ gross capacities. This caused the inundation of 26 villages, the relocation of 1149 households (with 5384 inhabitants) and the loss of about 6000 ha of agriculture and forestry-based land.

The project area is sited in the western highlands of Central Vietnam at altitudes of $350 \mathrm{~m}$ to $1700 \mathrm{~m}$. The hydropower plant is constructed just at Yali Falls on the Sesan River. After completing the dam embankment, the Yali Falls with their scenic splendors were destroyed.

The dam is earth fill, with a crest elevation of $520 \mathrm{~m}$, upstream slope of 1:5 and downstream slope of 1:2. The spillway has an overflow crest elevation of 500 $\mathrm{m}$. Its peak outflow discharge at 1000 years probable flood is $10,500 \mathrm{~m}^{3} / \mathrm{sec}$ and maximum reservoir water level is $527.2 \mathrm{~m}$. The catchment area is $7445 \mathrm{~km}^{2}$. The average annual rainfall is $2200 \mathrm{~mm}$ per annum and runoff is 8515 million $\mathrm{m}^{3}$ per annum. The total construction cost was USD 614.78 million. The plant lifespan of YHPP is forecasted to be 48 years (1993-2040).

In order to meet plant-related environmental concerns, the environmental impacts of the plant were fully assessed qualitatively and partially estimated quantitatively in previous environmental studies by the Mekong Secretariat and Ministry of Energy. However, these studies ignored a wide range of environmental protection and compensation costs. Because these were not incorporated into the direct costs of the plant, the full cost of hydropower production was understated.

This study provides a comprehensive assessment of the main environmental protection and compensation costs of YHPP and incorporates them into its net present value (NPV) and electricity price (p).

This study did not attempt a cost-benefit analysis of any of the mitigation measures to see whether it is of benefit to the people and whether the ecosystems are large enough to justify the costs of these measures. Our assumption is simply that the ecosystems should be returned to an approximation of its pre-dam state. Failing that, compensation should be provided to the people who are directly af- 
fected. The main objectives of this study are: to determine the full cost of YHPP by incorporating environmental and external costs into the direct costs of its hydropower production; to apply the principles of full cost electricity pricing and electricity user pays for YHPP environmental and external costs and to estimate the financial effects of applying these principles on YHPP's net present value and electricity price; to recommend policies and to apply these principles to electricity generation in Vietnam.

\section{Literature Reviews}

Sichilalu et al. (2019) [2] used the optimal model to plan water pump back for hydropower plants. The authors measured the opportunity cost of environmental regulatory policies to the performance of a hydropower system. The nonlinear operating cost model of the virtual power plant and the autoregressive-moving-average (ARMA) models were used by Jichun et al. (2019) [3] to point out the weighted output of hydro, photovoltaic, and thermal power; the sizing model of the virtual power plant was established, considering investment and complementary benefits. The study evaluated the trade-offs between economic and environmental performance of an autonomous energy system utilizing an existing Micro hydropower plant while improving its future reliability. A preliminary assessment was conducted using hypothetical future shortfall in electricity supply from a Micro hydro of $10 \%, 20 \%$ and $30 \%$, compared to a baseline of $2 \%$ shortfall, which shows drastic increase in the environmental costs (combined human health and ecological costs) by as much as $400 \%, 900 \%$, and $1400 \%$, respectively from continued use of conventional Diesel Genset. In the next step, Apichonnabutr \& Tiwary (2018) [4] used a "Micro hydro sustainability indicator" which is formulated as the ratio of environmental costs to net present costs of different hybrid options. This framework was implemented in a demonstration case study at the Khun Pang micro hydropower project in $\mathrm{Si}$ Lanna National Park within Chiang Mai province, northern Thailand for two scenarios-Scenario 1 (circa 2016-17, annual shortfall of $4 \%$ i.e. $571 \mathrm{~kW} \mathrm{~h}$ ) and Scenario 2 (circa 2025, projected future annual shortfall of 12.5\% i.e. $3904 \mathrm{kWh}$ ).

The diesel/small hydro/battery was found to be the most viable economic system for Southern Cameroons with a $0.443 \$ / \mathrm{kWh}$ energy cost. The optimum system was proven to be very resilient to variations in stream-flow, interest rate, fuel price, and PV cost. This outcome was found to be highly relevant to policymakers and investors in Cameroon (Muh \& Tabet, 2019) [5]. Based on the results, Yazdi \& Moridi (2018) [6] supplied various demands such as environmental demands of the aquatic ecosystem with high reliability as well as generating firm hydropower energy through the optimal design of cascade hydropower reservoirs. Jesper (2018) [7] found that the environmental benefits that the current policies are likely to accomplish could be achieved at well under half the cost in the Mörrum system, and at less than a tenth of the cost in the Ångerman system.

The mathematical models were developed by (Singh \& Singal, 2017) [8] for 
the operation of hydropower and techniques to minimize the operation cost as well as maximization of energy generation of hydropower plants. It has been found that earlier studies mainly focused on the operation of reservoir based hydropower plants and further studies are required for optimum operation of the run of river small hydropower plants. Pang et al. (2015) [9] evaluated the ecological impacts of small hydropower plants based on an energy analysis of a plant located in Guizhou Province in southwest China. The current costs of hydropower exceed alternatives, and the costs of these alternatives are likely to fall substantially below those of hydropower, while the environmental damages from the dams will be extensive and irreversible (Kahn et al., 2014) [10]. The periodic downstream drying-up of the river is the largest contributor to the induced ecological impacts in terms of energy cost. Therefore, China should rigorously investigate potential ecological problems of SHP development and proceed with caution rather than readily believing unjustified assumptions. Annual losses increase quadratically as a function of the maximum ramping rates and almost linearly as a function of the minimum environmental flows (Guisández et al., 2013) ([11]. Comparing the cost of generating electricity with coal and wind in Chile, Galetovic (2013) [12] estimated that the levelized cost of coal, including externalities, is $\$ 84 / \mathrm{MWh}$, on average. It is efficient to abate air pollutants ( $\mathrm{SOx}$, NOx, and PM2.5) but not $\mathrm{CO}_{2}$. With abatement, the cost wrought by environmental externalities equals $\$ 23 / \mathrm{MWh}$ or $27 \%$ of the total cost. Depending on the price of coal, the levelized cost may vary between $\$ 72$ and $\$ 99 / \mathrm{MWh}$. The site geology and environmental issues were considered as the most important risks (Kucukali, et al 2011) [13]. More attention must be paid on environmental issues and monitoring of the facilities must be enabled with further laws or regulations (Kucukali, 2009) [14]. Hydropower on a small-scale is in most cases "run-of-river", with no dam or water storage, and is one of the most cost-effective and environmentally benign energy technologies to be considered both for rural electrification in less developed countries and further hydro developments in Europe (Bakis, 2007) [15] The marginal environmental cost of coal mining (MEC1) was VND 19,029.4 per tonne in 2010 or $5.5 \%$ of production cost. Of the MEC1, on-site and off-site cost is about $3.6 \%$ and $1.93 \%$ of production cost, respectively. The LR-MOC of coal electricity is VND 771.9 per $\mathrm{kWh}$ at transmission and VND 975.5 per kWh at distribution. The MEC (including MEC1 + marginal environmental cost of coal-burning) accounts for $16.6 \%$ at transmission and $13.9 \%$ at the distribution level (Nguyen Van Song and Nguyen Van Hanh, 2001) [16]. Being aware of the benefits from using hydropower plants, David A. Harpman (1999) [17] used market-based prices to estimate nonmarket values the short-run costs of restricting hydropower operations of Glen Canyon Dam, on the Colorado River in Arizona.

In summary, hydropower projects not only bring about positive impacts but also create negative impacts on the environment, resources, and human life. These negative costs (negative environmental and external costs) need to be in- 
cluded in the cost of each KWh of electricity in order to properly and fully determine the costs that the society must pay for hydropower generation.

\section{Methodologies}

Information was first collected from published sources about the physical impacts of YHPP (Francisco and Glover 1999) [18]. In particular, it drew on the impact assessments in the original Environmental and Financial Studies by the Mekong Secretariat and the Vietnamese Ministry of Energy. Beside from the above secondary data, on-site surveys data have been conducted. Twelve (12) impacts are assessed as the following: meteorology, hydrology, water supply, erosion and sedimentation, land-use, forestry, watershed management, fauna, water quality and aquatic life, induced seismicity, public health, compensation and resettlement. Monetary values for each are estimated using procedures described detail in the section IV.

This then incorporated the monetized environmental and external costs into the direct costs of hydropower production of the plant in order to determine its full cost

$$
C_{f t}=C_{d t}+C_{e t},
$$

in which:

$C_{f t}$ is full cost in year $t$ of the plant.

$C_{d t}$ is direct cost in year $\mathrm{t}$ of the plant that consists of investment cost and operation - management - amortization cost.

$C_{e t}$ are environmental and external cost in year $\mathrm{t}$ of the plant that consists of its environmental, external, protection, compensation costs.

The $C_{d t}$ of YHPP is calculated in the original financial study for the plant, while the $C_{e t}$ is valued by this study, considering the twelve environmental factors as follows:

$$
C_{e t}=\sum_{k=1}^{12} C_{e k t}
$$

in which: $C_{e k t}$ is environmental cost related to the environmental factor $k$ in year $t$.

We then determined the net present value (NPV) of the plant using two assumptions: with and without incorporating the environmental and external costs into the direct costs of the plant on condition that its direct cost-based price $\mathrm{p}$ is kept at the original level of 5.2 US cents/kWh (this electricity price is formally defined by electricity authorities for YHPP).

- Without incorporated YHPP environmental and external costs:

$$
N P V d=\sum_{n=1}^{N}\left(P Q-C_{d t}\right) /(1+i) t
$$

- Without incorporated YHPP environmental and external costs:

$$
N P V f=\sum_{n=1}^{N}\left(P Q-C_{d t}-C_{e t}\right) /(1+i) t
$$

in which: 
$P$ is direct cost-based electricity price

$Q$ is annual electricity quantity generated by the plant

$N$ is plant life of 48 years (1993-2040)

$i$ is standardized discount rates for the Vietnamese electricity sector $(8 \% ; 10 \%$; $12 \%)$.

We also explored a scenario in which the NPV was kept at its original value, while the electricity price was increased to a level that would allow incorporation of environmental and external costs. The full cost-based electricity price P' is determined by solving the following equation:

$$
\sum_{n=1}^{N}\left(\left(P Q-C_{d t}\right) /(1+i) t\right)=\sum_{n=1}^{N}\left(P^{\prime} Q-C_{d t}-C_{e t}\right) /(1+i) t
$$

Finally, we drew from this analysis some recommendations for full-cost electricity pricing for YHPP and for Vietnam in general.

\section{Results and Discussions}

\subsection{Valuation of Environmental and External Costs}

\subsubsection{Meteorology}

There is a negligible impact on the climate of the catchment area through the increase in local humidity. The only mitigation measure required is monitoring equipment valued at USD 2000 and disbursed entirely in 1993.

\subsubsection{Hydrology}

No significant adverse environmental effects are identified and no mitigation measures are required. However, existing monitoring stations need to be expanded and supplemented with new stations to improve flood warning and water level recording. This equipment would cost USD 350,455 disbursed over five years from 1993 to 1997. Therefore, depreciation cost is USD 70,091/per year.

\subsubsection{Water Supply}

There is no significant harmful effect on water supplies either for domestic consumption or for agriculture in the catchments, so no mitigation measures are required. However, the future growth of demand for irrigation water in the catchments will reduce runoff, and thus the YHPP's energy generation will be reduced by about $2 \%$ per annum. This effect is assessed through estimating the foregone revenue caused by the reduction of electricity generation:

5.2 US cents / kWh 2\% $2726 \mathrm{GWh} /$ year = USD 2,862,546/year.

This environmental cost is allocated over the period from 2001 (when all of four electricity generation units of the plant are functioning) to 2040, the last year of the plant's lifespan.

\subsubsection{Erosion and Sedimentation}

Estimated reservoir sedimentation is about 2.0 million $\mathrm{m}^{3} /$ year, half of which can be expected to penetrate deep into the reservoir's dead storage. This can lead to the reduction in lifespan storage of the reservoir of about $1 \%$ per year. Delta 
formation and flooding of Kontum town by an additional backwater effect could also occur. None of these three effects would have drastic consequences. Some reservoir bank erosion could occur at its west bank and near the dam. Mitigation of erosion and sedimentation can be accomplished through the measures described in Section 4.1.10, such as protecting the reservoir's shoreline by a forest belt and limiting agricultural activities and habitation.

In this section, we include a cost of USD 1000/year as the cost of monitoring these measures.

\subsubsection{Land Use}

Due to the construction of YHPP, a change in land use in the reservoir area occurred. The total area permanently and seasonally flooded by the reservoir is 6400 ha, of which 1700 ha of permanently flooded area and 4700 ha of seasonally flooded area have considerable potential for agricultural production and forestry. This total flooded area of 6400 ha comprises 1200 ha of agricultural land, 700 ha of forestry land, 3600 ha of uncultivated land and 900 ha of other land.

The loss of agricultural production value by flooding is estimated at USD 166,273 per annum. This loss is allocated annually from 2001 to 2040 . The cost of a study on the irrigation potential of a semi-impounded area is estimated at about USD 7688. The cost of realizing a pilot scheme on soil conservation and sedentarization of agriculture is estimated at USD 90,000.

The cost of monitoring the land use status is estimated at USD 655 per annum.

The total costs of the above USD 7688 and USD 90,000 is as allocated for the period from 1993 to 2000, i.e. the land-use related annual environmental cost, is

$$
\frac{7688+90,000}{8}+655=12,866 \mathrm{USD} / \text { year }
$$

In addition, two costs possibly attributed to land use change have been assessed elsewhere. Compensation for the loss of home-gardens flooded by reservoir is estimated in the discussion in Section 4.1.12 (Compensation and Resettlement) as a component of the total compensation for the relocated population. Compensation for forestry land flood by estimated and discussed in Section 4.1.7 (Watershed Management).

\subsubsection{Forestry}

During the construction phase of the plant, after completing the dam embankment in the project area, a forestry area of 3944 ha was lost due to the reservoir's flooding. This flooded forest area includes 114 ha of high value forests, 161 ha of medium value bamboo forests and 3669 ha of degraded mixed forests.

After building the powerhouse, access roads, and quarry sites etc., in the downstream area, 150 ha of high value forests were destroyed. The following losses are significant:

Loss of annual timber extraction from the flooded high and medium value forest area of $425 \mathrm{ha}$ (114 ha +161 ha $+150 \mathrm{ha}=425 \mathrm{ha})(B a n n, 1998)$ [19].

Loss of annual timber extraction from the flooded degraded forest area of 
3669 ha (Bann, 1998) [19].

Loss of local households' income from exploitation of non-timber forest products of flooded forest areas.

Costs of forming protection forests by replanting degraded forests and protection against fire and illegal logging. These forestry-related activities were from an independent program for forestry development in western high lands' areas in order to compensate for the forest areas flooded by the YHPP reservoir.

The forestry-related environmental and external costs are estimated on the basis of the following data:

The annual timber extraction figure per hectare of rich and medium forest in Gia Lai and Kontum provinces is estimated at $54.63 \mathrm{~m}^{3} /$ ha/year (Mekong Secretariat and Ministry of Energy 1992 Vol. II).

The annual timber extraction figure per hectare of degraded (poor) forests in Gia Lai and Kontum provinces is estimated at $8-12 \mathrm{~m}^{3} / \mathrm{ha} /$ year. These are estimated from interviews with senior forestry specialists of Gia Lai and Kontum provinces.

The average annual income from exploiting non-timber forest products by local households is estimated at USD 155/household/year. These are estimated from household surveys in similar parts of Vietnam (Mekong Secretariat and Ministry of Energy 1992 [20]; Francisco and Glover 1999, [18]).

The costs of the program of afforestation, reforestation, re-planting and forest protection are estimated by the environmental management and monitoring plan for YHPP project (Mekong Secretariat and Ministry of Energy 1992 Vol. IV), [20].

The average unit sale price of timber in Gia Lai and Kontum provinces is USD $17.05 / \mathrm{m}^{3}$ (Mekong Secretariat and Ministry of Energy 1992 Vol. V) [20].

Estimated monetary values for the area in question are as follows.

Fist, loss of annual timber extraction from flooded forest area of 425 ha: (114 ha +161 ha +150 ha $=425$ ha). USD 396,115/year. Second, loss of annual timber extraction from flooded degraded forest areas of 3669 ha: USD 618,255/year. Third, loss of local households' income from exploiting non-timber forest products: USD 98,739/year. Fourth, costs of the forestry development program in areas located near YHPP in order to compensate for the forest areas flooded by the reservoir of the plant: 1) During eight years (1993-2000) of construction phase: USD 177,024 /year 2) During the first 10 years (2001-2010) of operation phase: USD 339,909/year.

\subsubsection{Watershed Management}

Watershed management requires a set of measures for the development and reform of forestry and agriculture as well as the environmental protection and monitoring within the YHPP project area. These costs would be realized during the construction phase (1993-2000) and the first 10 years of YHPP operation phase (2001-2010) (Mekong Secretariat and Ministry of Energy 1992 Vol. IV) [20]. These estimated costs are as follows: First, during the construction phase 
(1993-2000): USD 45,455/8year or USD 5688/year. Second, during the operation phase (2001-2010): USD 84,500/10 year or USD 8450/year. Third, additional replanting (1993-1997): USD1111/year.

\subsubsection{Fauna}

The protection of indigenous fauna within the YHPP catchment area is considered as an important part of the watershed management. For the project area, it is necessary to create and preserve the reservoir shoreline wetland vegetation (i.e. the semi - impounded vegetation belt) for protecting the reservoir's shore, which are shelters for indigenous fauna.

The total fauna protection-related cost is estimated at USD 300,000, allocated principally for the construction phase of 8 years from 1993 to 2000 (USD 37,500 per annum).

\subsubsection{Water Quality, Aquatic Life and Fisheries}

Due to the small storage and short retention time of the Sesan River water within the YHPP reservoir, there is little danger of oxygen depletion and negligible negative effects on the quality of out-flowing water. At the same time, the change from running river water with low nutrient content to stagnant reservoir water may slightly increase the number of fish species and other fauna.

Environmental and external costs are preventive expenditures for monitoring and managing the water quality through additional instruments to analyze its temperature, $\mathrm{pH}$, oxygen content etc. and for developing new fishing systems after reservoir filling. This cost is allocated as listed below: Fist, additional instruments for analyzing water quality USD 3000; Second, development of new reservoir fishing infrastructure USD 7600; the total is USD10,600.

\subsubsection{Reservoir-Induced Seismicity}

The environmental and external costs relating to reservoir-induced seismicity are the preventive expenditures for investigating and monitoring the reservoir-induced seismic hazards at the dam site. The costs of an up to date micro-seismic network recommended for YHPP are estimated at USD 64,890 disbursed over 5 years (1993-1997), i.e. USD 12,978 per annum.

\subsubsection{Public Health and Water-Borne Diseases}

In general, due to the change from running river water to stagnant reservoir water and the considerable resettlement by forming the YHPP reservoir, there is the possibility of mass development of disease vectors and the increasing exposure of the local population to these vectors. These can lead to diseases like malaria, diarrhea, dysentery and intestinal parasitic diseases.

Preventive and curative health care for affected local population consist of the following items:

First, building of four new village health stations USD 24,000; Second, renovation of eight existing health centers USD 77,334; The total public health-related new investment costs USD 101,334. This cost is disbursed during the YHPP 
construction phase from 1993 to 2000, i.e. the public health-related annual new investment cost is USD 12,677/year. Third, running of 12 preventive medicine programs USD 1,982,667/year. Fourth, realizing the popular health education program USD 662,800/year. Total operation and management costs of these programs USD 2,645,467/year.

This total operation and management costs is allocated for the first 10 years of the YHPP operation phase, i.e. from 2001 to 2010. (Mekong Secretariat and Ministry of Energy 1992; Vol. II, IV and V) [20].

\subsubsection{Compensation and Resettlement}

The total relocated population consists of 1149 households with 5384 inhabitants living in 846 houses in 26 villages, amongst which are 10 fully flooded villages and 16 partially flooded ones. The public infrastructures affected by YHPP reservoir are: $6.8 \mathrm{~km}$ of provincial road; $25.6 \mathrm{~km}$ of rural road; four small bridges; five culverts; $6.8 \mathrm{~km}$ of telephone lines and several houses, schools, crèches, health care stations, shops and offices of people's committees. The agricultural area affected by reservoir flooding is 1933 ha. These are planted with rice, auxiliary crops and perennial trees.

There are two alternatives for the estimation of compensation and resettlement- related costs:

Alternative 1. This is purely based on the compensation cost only, which is defined according to the Decree No. 90/CP of the Government. The relocated households and local authorities of flooded communes could use these compensation payments to build themselves new housing in the resettlement area. Using this alternative, the compensation and resettlement - related costs consist of the following items: First, resettlement expenditures used to compensate for property losses only USD 16,132,243. Second, clearing of trees in reservoir bed USD 992,734. Third, cost of afforestation USD 445,332. Total cost is USD 17,570,309

Alternative 2. This adds the costs of building infrastructure in the new resettlement areas:

First, resettlement expenditures not only to compensate for property losses but also for building new complete resettlement areas USD 26,373,339. Second, clearing of trees in reservoir bed USD 992,734. Third, cost of afforestation USD 445,332 . Total is USD $27,811,405$.

Alternative 2 has been selected as the preferred one although its costs are greater because resettlement would be more thorough. (It would include construction of infrastructure like the irrigation, and allow compensation for disruption and loss of intangible assets.)

The compensation and resettlement-related costs of USD 27,811,405 are assumed to be allocated for the period from 1993 to 1997 (USD 5,562,281 per annum).

(PIDC 1 1994) [21]; (People's Committee of Kontum Province 1994) [22].

\subsubsection{Other Effects}

In addition, four other effects were investigated. They were found to be of neg- 
ligible magnitude. These are vegetation, groundwater, mineral and radioactive deposits, and archeological/recreational sites.

\subsubsection{Results}

The major environmental and external costs of Yali Hydropower Plant are summarized and discounted with standardized discount rates of $8 \%, 10 \%$ and $12 \%$ for the whole plant lifespan from 1993 to 2040. These values are presented in Table 1 below and analyzed net present value and electricity price with and without environmental and external costs.

The largest single item is compensation and resettlement, which accounts for about one-third of environmental and external costs. Effects on forestry, water supply and public health are also significant, each accounting for about one-fifth of the costs. Together, these account for over 97\% of YHPP's environmental and external costs.

\subsection{Electricity Price with and without Environmental and External Costs}

The NPV and the electricity price $(\mathrm{P})$ are the two most important financial criteria that are used for estimating the financial viability of electric power plants in Vietnam. For YHPP, these criteria are considerably influenced by incorporating the environmental and external costs into the direct costs of the plant to determine its full costs.

Table 1. Environmental and external Costs of Yali Hydropower Plant.

\begin{tabular}{|c|c|c|c|c|c|c|c|}
\hline \multirow{3}{*}{ No. } & \multirow{3}{*}{$\begin{array}{l}\text { Environmental } \\
\text { and external } \\
\text { impacts on }\end{array}$} & \multicolumn{6}{|c|}{ Standardized discount rate } \\
\hline & & \multicolumn{2}{|l|}{$8 \%$} & \multicolumn{2}{|l|}{$10 \%$} & \multicolumn{2}{|l|}{$12 \%$} \\
\hline & & $\begin{array}{l}\text { Discounted Envir. \& } \\
\text { External costs (USD) }\end{array}$ & $\begin{array}{l}\text { Percent. } \\
\text { in total }\end{array}$ & $\begin{array}{l}\text { Discounted Envir. \& } \\
\text { External costs (USD) }\end{array}$ & $\begin{array}{l}\text { Percent. } \\
\text { in total }\end{array}$ & $\begin{array}{l}\text { Discounted Envir. \& } \\
\text { External costs (USD) }\end{array}$ & $\begin{array}{l}\text { Percent. } \\
\text { in total }\end{array}$ \\
\hline 1 & Meteorology & 1852 & - & 1818 & - & 1786 & - \\
\hline 2 & Hydrology & 283,846 & 0.3 & 269,491 & 0.5 & 256,267 & 0.5 \\
\hline 3 & Water Supply & $16,705,411$ & 22.7 & $11,829,276$ & 19.9 & $8,633,456$ & 17.4 \\
\hline 4 & Erosion and Sedimentation & 6422 & - & 4562 & - & 3330 & - \\
\hline 5 & Land Use & $1,145,151$ & 1.6 & 827,177 & 1.5 & 617,524 & 1.3 \\
\hline 6 & Forestry & $15,814,862$ & 21.5 & $12,933,116$ & 21.8 & $10,889,128$ & 22.1 \\
\hline 7 & Watershed Management & 64,085 & - & 55,276 & - & 48,200 & - \\
\hline 8 & Fauna & 215,499 & 0.3 & 200,060 & 0.4 & 186,287 & 0.4 \\
\hline 9 & Water Quality & 5303 & - & 4495 & - & 3822 & - . \\
\hline 10 & Reservoir-induced Seismicity & 51,817 & - & 49,197 & - & 46,783 & - \\
\hline 11 & Public Health & $17,116,222$ & 23.3 & $12,136,208$ & 20.4 & $8,871,073$ & 17.9 \\
\hline \multirow[t]{2}{*}{12} & Compensation and Resettlement & $22,208,617$ & 30.3 & $21,085,461$ & 35.5 & $20,050,807$ & 40.4 \\
\hline & Total & $73,619,087$ & 100.0 & $59,396,137$ & 100.0 & $49,608,465$ & 100.0 \\
\hline
\end{tabular}

Note: Exchange rate $1 \$=23,350 \mathrm{VND}$ (October, 2019). 
In this section, the NPV and Price (P) are calculated on the basis of formulae presented in Section III. (Methodology) for the following cases: Original case: without incorporating the YHPP environmental and external costs into the costs of the plant; its electricity price is kept at the original level p of 5.2 US cents $/ \mathrm{kWh}$. This is the original case of the YHPP original financial appraisal with its direct cost - based net present value NPVd and electricity price $\mathrm{p}$ (See formulae presented in Section III). Second case, with incorporating the YHPP environmental and external costs into the direct costs of the plant but maintaining the electricity price at the original level $\mathrm{p}$ of 5.2 US cents/kWh. In this case, the YHPP's net present value and thus its financial viability is decreased. Third case, with incorporating the YHPP environmental and external costs into the direct costs of the plant while increasing the electricity price of the plant so that its net present value, that is, its financial viability is kept unchanged at the original level of NPVd (see formulae presented in Section III).

In the YHPP's original financial appraisal, the environmental and external costs of the plant were not considered or incorporated into its costs. This means that the net present value NPVd $=$ USD 219,520,140 and the electricity price $\mathrm{P}=$ 5.2 US cents/kWh mentioned in this financial appraisal are only the direct cost based ones. If environmental and external costs of the plant are incorporated while its electricity price is kept unchanged at the original value of $p=5.2$ US cents/kWh, the net present value is decreased to NPVf $=$ USD 160,124,000. If the net present value of the plant is maintained at NPVd $=$ USD 219,520,140 while its environmental and external costs are incorporated, the electricity price needs to be increased to price $\mathrm{P}^{\prime}=5.68$ US cents (see Table 2).

\section{Conclusions and Policy Recommendations}

The results of this study pointed out that if the electricity price is maintained at its original level of 5.2 US cents/kWh to cover direct production costs only, the net present value of the YHPP would be reduced to about $27 \%$ by incorporating

Table 2. Effects of Incorporating Environmental and External Costs on YHPP's NPV and Electricity price.

\begin{tabular}{lccc}
\hline Case & Original & Second & Third \\
\hline $\begin{array}{l}\text { Assumptions of } \\
\text { calculations }\end{array}$ & • Without incorporated & - With incorporated & • With incorporated \\
& YHPP environmental & YHPP environmental & YHPP \\
& - Direct cost - based & - Direct cost - based & environmental and \\
& electricity price & electricity price & - Full cost - based \\
& (original) of 5.2 US & (original) of 5.2 US & electricity price \\
& cents/kWh. & cents/kWh. & (increased) \\
& - Original net present & - Decreased net present & - Original net present \\
& value (NPVd). & value (NPVf). & value (NPVd). \\
NPV (USD) & NPVd = 219,520,140 & NPVf = 160,124,000 & NPVd = 219,520,140 \\
P (US cents/kWh) & P $=5.20$ & P = 5.20 & P' = 5.68 \\
\hline
\end{tabular}

Note: Exchange rate $1 \$=23,350$ VND (October, 2019). Using the standardized discount rate of $10 \%$. 
environmental and external costs. Alternatively, the true electricity price of the YHPP would have to be increased to $5.68 \mathrm{US}$ cents/kWh in order to cover the full costs of YHPP. This price is included not only direct cost but also included environmental and external cost of YHPP. It is maintained the original net present value.

This study recommends that electricity pricing should be revised, not only to eliminate direct government subsidies, but also to incorporate the environmental and external costs of electricity production. Current pricing policies do not achieve this. Environmental and external costs may not be explicitly recognized, but they are still paid. They come in the form of damages to health and ecosystems, or relocation of affected people, and are most often paid by vulnerable groups and future generations.

Incorporating these costs in the price of electricity would have several advantages. These are:

First, it would make environmental and external costs more visible, and thus more pressure will be exerted to minimize them.

Second, it would implement the widely accepted principle of "polluter pays", making it possible to assign the payment of environmental and external costs to the activities that generate these costs.

Third, if applied to all forms of power generation, it would provide appropriate incentives for the generation of environmentally-friendly energy sources.

Fourth, it would provide incentives to reduce energy consumption through demand-side measures, such as reducing transmission losses, adopting energy saving technologies, shifting to less-energy intensive industries, and so on.

Fifth, it would provide revenue with which the environmental mitigation and compensation activities associated with power generation could actually be undertaken.

This study therefore recommends that full-cost electricity pricing-incorporating environmental and external costs-be applied to all forms of energy generation in Vietnam. Studies would be required for each energy source in order to assess their environmental and external costs.

In the case of YHPP, the price increase recommended is from 5.2 to 5.68 US cents/kWh-a $10 \%$ increase. This is not an exorbitant amount. Furthermore, it should be emphasized that these costs are already being paid through losses of forest benefits, damages to public health, disruption to the lives of people relocated because of dam construction and so on. Full cost electricity production simply reallocates these costs according to the "polluter pays" principle. In doing so, it makes the costs visible and creates incentives to reduce them.

We therefore make the following specific recommendations:

First, full-cost pricing should be applied to all forms of electricity generation in Vietnam;

Second, revenue from the additional changes for environmental and external costs should be put into a fund that would be used to pay for the prevention, mi- 
tigation and compensation costs accordingly;

Third, in the case of Yali Hydropower Plant, the electricity price should be increased from 5.2 to 5.68 US cents/kWh.

We believe these policy changes would help put Vietnam's power sector on a path that is economically and environmentally sustainable.

\section{Conflicts of Interest}

The authors declare no conflicts of interest regarding the publication of this paper.

\section{References}

[1] Institute of Energy (1998) Vietnam Electricity Development Master Plan for the Period 2000-2010 in Perspective up to the Horizon 2020. Hanoi, Vietnam.

[2] Sichilalu, S., Wamalwa, F. and Akinlabi, E.T. (2019) Optimal Control of Wind-Hydrokinetic Pumpback Hydropower Plant Constrained with Ecological Water Flows. Renewable Energy, 138, 54-69. https://doi.org/10.1016/j.renene.2019.01.030

[3] Liu, J.C., Li, J.H., Xiang, Y., Zhang, X. and Jiang, W.X. (2019) Optimal Sizing of Cascade Hydropower and Distributed Photovoltaic Included Virtual Power Plant Considering Investments and Complementary Benefits in Electricity Markets. Energies, 12, 1-23. https://doi.org/10.3390/en12050952

[4] Apichonnabutr, W. and Tiwary, A. (2018) Trade-Offs between Economic and Environmental Performance of an Autonomous Hybrid Energy System Using Micro Hydro. Applied Energy, 226, 891-904. https://doi.org/10.1016/j.apenergy.2018.06.012

[5] Muh, E. and Tabet, F. (2019) Comparative Analysis of Hybrid Renewable Energy Systems for Off-Grid Applications in Southern Cameroons. Renewable Energy, 135, 41-54. https://doi.org/10.1016/j.renene.2018.11.105

[6] Yazdi, J. and Moridi, A. (2018) Multi-Objective Differential Evolution for Design of Cascade Hydropower Reservoir Systems. Water Resources Management, 32, 4779-4791. https://doi.org/10.1007/s11269-018-2083-5

[7] Stage, J. (2018) Living in a Bubble: Potential Gains from Flexible Water Management Policies. Applied Economics Letters, 25, 1368-1372.

https://doi.org/10.1080/13504851.2017.1420882

[8] Singh, V.K. and Singal, S.K. (2017) Operation of Hydro Power Plants: A Review. Renewable and Sustainable Energy Reviews, 69, 610-619. https://doi.org/10.1016/j.rser.2016.11.169

[9] Pang, M.Y., Zhang, L.X., Ulgiati, S. and Wang, C.B. (2015) Ecological Impacts of Small Hydropower in China: Insights from an Energy Analysis of a Case Plant. Energy Policy, 76, 112-122. https://doi.org/10.1016/j.enpol.2014.10.009

[10] Kahn, J.R., Freitas, C.E. and Petrere, M. (2014) False Shades of Green: The Case of Brazilian Amazonian Hydropower. Energies, 7, 1-20. https://doi.org/10.3390/en7096063

[11] Guisández, I., Pérez-Díaz, J.I. and Wilhelmi, J.R. (2013) Assessment of the Economic Impact of Environmental Constraints on Annual Hydropower Plant Operation. Energy Policy, 61, 1332-1343. https://doi.org/10.1016/j.enpol.2013.05.104

[12] Galetovic, A. and Muñoz, C.M. (2013) Wind, Coal, and the Cost of Environmental 
Externalities. Energy Policy, 62, 1385-1391.

https://doi.org/10.1016/j.enpol.2013.07.140

[13] Kucukali, S. (2011) Risk Assessment of River-Type Hydropower Plants Using Fuzzy Logic Approach. Energy Policy, 39, 6683-6688.

https://doi.org/10.1016/j.enpol.2011.06.067

[14] Kucukali, S. and Baris, K. (2009) Assessment of Small Hydropower (SHP) Development in Turkey: Laws, Regulations and EU Policy Perspective. Energy Policy, 37, 3872-3879. https://doi.org/10.1016/j.enpol.2009.06.023

[15] Bakis, R. (2007) Electricity Production Opportunities from Multipurpose Dams (Case Study). Renewable Energy, 32, 1723-1738. https://doi.org/10.1016/j.renene.2006.08.008

[16] Van Song, N. and Van Hanh, N. (2001) Electricity Pricing for North Vietnam. EEPSEA Research Report rr2016035, Economy and Environment Program for Southeast Asia (EEPSEA). http://hdl.handle.net/10625/27690

[17] Harpman, D.A. (1999) Assessing the Short-Run Economic Cost of Environmental Constraints on Hydropower Operations at Glen Canyon Dam. Land Economics, 75, 390-401. https://doi.org/10.2307/3147185

[18] Francisco, H. and Glover, D. (1999) Economy and Environment. Case Studies in Vietnam. EEPSEA, Singapore, 167-170.

[19] Bann, C. (1998) The Economic Valuation of Tropical Forest. Land Use Option: A Manual for Researchers. EEPSEA, Singapore, 117-126.

[20] Mekong Secretariat and Ministry of Energy (1992) (Current Is Ministry of International Trade and Industry, 2018). Environmental and Financing Studies on the Yali Falls Hydropower Project (Basin Wide)-Draft Final Report. Hanoi, Vietnam. Vol. I, II, III, IV, V.

[21] PIDC 1 (Power Investigation and Design Company No 1) (1994) Environmental Impact Assessment for Yali Falls Hydropower Project. Chapter 7. Compensation and Resettlement. Investigation Report. Hanoi, Vietnam.

[22] People's Committee of Kontum Province (1994) Investment Project for Socio-Economic Development of Resettled Villages within Yali Hydropower Reservoir Area. Project Paper, Kontum, Vietnam. 